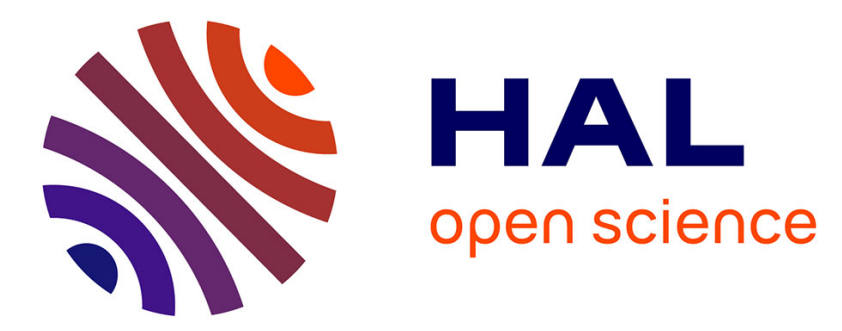

\title{
Long-term wine consumption is related to cardiovascular mortality and life expectancy independently of moderate alcohol intake: the Zutphen Study
}

M T Streppel, M C Ocké, H C Boshuizen, F J Kok, D Kromhout

\section{- To cite this version:}

M T Streppel, M C Ocké, H C Boshuizen, F J Kok, D Kromhout. Long-term wine consumption is related to cardiovascular mortality and life expectancy independently of moderate alcohol intake: the Zutphen Study. Journal of Epidemiology and Community Health, 2009, 63 (7), pp.534-n/a. 10.1136/jech.2008.082198 . hal-00477884

\section{HAL Id: hal-00477884 \\ https://hal.science/hal-00477884}

Submitted on 30 Apr 2010

HAL is a multi-disciplinary open access archive for the deposit and dissemination of scientific research documents, whether they are published or not. The documents may come from teaching and research institutions in France or abroad, or from public or private research centers.
L'archive ouverte pluridisciplinaire HAL, est destinée au dépôt et à la diffusion de documents scientifiques de niveau recherche, publiés ou non, émanant des établissements d'enseignement et de recherche français ou étrangers, des laboratoires publics ou privés. 
1 Long-term wine consumption is independently of moderate alcohol intake related to

2 cardiovascular mortality and life expectancy. The Zutphen Study.

3 Martinette T Streppel ${ }^{1,2}$, Marga C Ocké ${ }^{1}$, Hendriek C Boshuizen ${ }^{1}$, Frans J Kok ${ }^{2}$, Daan Kromhout ${ }^{2}$

$4{ }^{1}$ National Institute for Public Health and the Environment (RIVM), Bilthoven, the Netherlands

$5 \quad 2$ Division of Human Nutrition, Wageningen University, Wageningen, the Netherlands

6

8 Keywords: wine, alcohol, cardiovascular, mortality, life expectancy

10 Word count: 3,692; excluding title page, references, figure legends and tables

\section{Corresponding author:}

14 Martinette T Streppel

15 Division of Human Nutrition

16 Wageningen University

$17 \quad$ P.O. Box 8129

$18 \quad 6700$ EV Wageningen

19 The Netherlands

$20 \quad$ Tel. +31317482880

$21 \quad$ Fax: +31317482782

22 martinette.streppel@wur.nl 
1 Background: Light to moderate alcohol intake lowers the risk of cardiovascular mortality, but

2 whether this protective effect can be attributed to a specific type of beverage remains unclear.

3 Moreover, little is known about the effects of long-term alcohol intake on life expectancy.

4 Methods: The impact of long-term alcohol intake and types of alcoholic beverages consumed on

5 cardiovascular mortality and life expectancy at age 50 was investigated in the Zutphen Study, a

6 cohort of 1,373 men born between 1900 and 1920, and examined repeatedly between 1960 and

7 2000. Hazard ratios for total alcohol intake and alcohol from wine, beer and spirits were obtained

8 from time-dependent Cox regression models. Life expectancy at age 50 was calculated from

9 areas under survival curves.

10 Results: Long-term light alcohol intake, i.e. $\leq 20$ grams per day, compared to no alcohol, was

11 strongly and inversely associated with cerebrovascular (HR: 0.43 [0.26-0.70]), total

12 cardiovascular (HR: 0.70 [0.55-0.89]) and all-cause mortality (HR: 0.75 [0.63-0.91]).

13 Independent of total alcohol intake, long-term wine consumption of, on average, less than half a

14 glass per day was strongly and inversely associated with coronary heart disease (HR:0.61 [0.41-

$150.89]$ ), total cardiovascular (HR: 0.68 [0.53-0.86]) and all-cause mortality (HR: 0.73 [0.62-0.87]).

16 These results could not be explained by differences in socioeconomic status. Life expectancy was

17 about 5 years longer in men who consumed wine compared to those who did not use alcoholic

18 beverages.

19 Conclusion: Long-term light alcohol intake lowered cardiovascular and all-cause mortality risk,

20 and increased life expectancy. Light wine consumption was associated with a 5 years longer life

21 expectancy; however, more studies are needed to verify this result. 
1 Many studies have demonstrated a U- or J-shaped relationship between alcohol intake and all-

2 cause mortality. This association can be explained by a lower risk of cardiovascular disease

3 (CVD) mortality in light to moderate drinkers (1-4). The protective effect of light to moderate

4 alcohol intake may be due to an increase in HDL cholesterol and prevention of blood clotting and

5 reduction of platelet aggregation (5;6). Red wine consumption may have an additional health

6 benefit because of its polyphenolic compounds $(7 ; 8)$ that interfere with the initiation, progression

7 and rupture of atherosclerotic plaques (9), and improve endothelial function (10;11). Although

8 some epidemiological studies showed beneficial effects of wine consumption (12;13), results of

9 several other studies do not show an advantage of one type of alcoholic beverage over another

10 (14). Studies have suggested that the beneficial effects of wine consumption compared to other

11 beverages can mainly be attributed to differences in socioeconomic status, dietary and other

12 lifestyle habits $(15 ; 16)$.

13 In prospective cohort studies in which alcohol intake is only assessed at the baseline

14 examination, consumption patterns are assumed to be relatively constant over the entire study

15 period. However, it is unlikely that exposure measurements in the past accurately reflect long-

16 term alcohol intake since consumption patterns usually change during life. To get correct

17 estimates of long-term effects of alcohol intake, repeated measures are needed. Moreover, the use

18 of repeated measures, especially when using a cumulative average method, reduces within-

19 subject variation over time and, thereby, misclassification in alcohol intake (17).

20 In epidemiological studies, hazard ratios are commonly used to express the impact on

21 mortality. Since hazard ratios express effects for an exposed group relative to the effect of the

22 unexposed group, they do not provide information regarding absolute health effects. Such insight

23 can be obtained by the calculation of life expectancies and the number of life-years lost. 
1 Although concepts like life expectancy are more informative and easier to understand, they are 2 not reported frequently.

3 The objective of the present study is to assess the relationship between long-term intake

4 of alcohol and the types of alcoholic beverages consumed, and cardiovascular and all-cause

5 mortality. To obtain more accurate effect estimates, we used seven repeated measures of the

6 consumption of alcoholic beverages. In addition to hazard ratios, we present our results also in

7 terms of differences in life expectancy. 
METHODS

\section{Study population}

3 The Zutphen Study has been carried out since 1960 among middle-aged men in Zutphen, an old

4 industrial town in the eastern part of the Netherlands with about 30,000 inhabitants. In 1960, a

5 random sample was drawn of 1,088 men born between 1900 and 1919 and residing for at least 5

6 years in Zutphen. Of those men, 878 participated in the Zutphen Study (response rate: 81\%).

7 Examinations were repeated in 1965, 1970, 1985, 1990, 1995 and 2000. In 1985, the group of

8554 survivors was extended with a new random sample of men of the same age. Of the 1266 men

9 who were invited in 1985, 939 men participated (response rate: 74\%). In every examination

10 round, the participants that took part in both the dietary and physical examinations were selected

11 for the present study (1,373 men).

12 Baseline data were collected in 1960 before the Helsinki Declaration was developed and

13 oral informed consent was obtained in view of follow-up data. In 1985 and 1990, the study was

14 approved by the Medical Ethics Committee of the University of Leiden, The Netherlands, and in

151995 and 2000, by the Medical Ethics Committee of the Netherlands Organisation for Applied

16 Scientific Research (TNO).

\section{Assessment of alcohol and food consumption}

19 The habitual alcohol consumption was assessed as part of the total diet, using the cross-check

20 dietary history method (18), adapted to the Dutch situation (19;20). This method provides

21 information about the participant's usual food and alcohol consumption pattern, 6 to 12 months

22 preceding the interview. From 1985 onwards, the information about the usual food and alcohol

23 consumption pattern was limited to the month preceding the interview because consumption

24 patterns from 1985 were much more complicated than those in the 1960s. The daily intake of 
1 alcohol, energy and other nutrients was calculated using food composition tables close to the year

2 of measurement (21-23). Alcohol intake was highly reproducible $(r=0.8)(24)$ and ranking of the

3 participants was considered valid as shown by the strong correlation with HDL cholesterol (25).

4 To assess the relationship between different types of alcoholic beverages and mortality,

5 we calculated the alcohol intake from wine, beer or spirits, respectively. Participants were

6 grouped into three categories according to their intake of total alcohol and of alcohol from beer,

7 wine or spirits: $0,>0-20$, and $>20 \mathrm{~g} / \mathrm{d}$. Since studies have suggested that using non-drinkers as a

8 reference group is unsuitable for studying the effects of alcohol on mortality because of the

9 higher background risk among the former drinkers (26-28), we created a time-dependent

10 indicator variable for those men who stopped drinking during follow-up.

\section{Assessment of potential confounders}

13 Detailed information on type and amount of smoking was collected using standardized

14 questionnaires. Cigarette, cigar or pipe smokers were divided into categories of never or long-

15 term ex-smokers, i.e. stopped smoking $\geq 10$ years ago, recent ex-smokers, i.e. stopped smoking

$16<10$ years ago, and current smokers. Also, the number of years of cigarette smoking was

17 calculated. During physical examinations men's weight and height were measured and body mass

18 index (BMI) was calculated. Information about the prevalence and history of clinical myocardial

19 infarction (MI), stroke, diabetes mellitus (DM), and cancer was collected throughout the study.

20 The men were classified into four levels of socioeconomic status (manual workers, non-manual

21 workers, small business owners and professionals) according to occupation at baseline.

23 Case ascertainment 
1 Participants were followed until death, or censored on June 30th, 2000. Three participants were

2 lost to follow-up during the study and were censored after their last physical examination.

3 Information about the causes of death was available from the official death certificate, the

4 medical history collected from interviewing physicians or relatives of the dead person and other

5 witnesses, and from abstracts of hospital and other medical records (29). The adjudication of the

6 underlying causes of death were done by one clinical epidemiologist (Dr Alessandro Menotti,

7 Association for Cardiac Research, Rome, Italy) and coded according to the International

8 Classification of Diseases; Eight Revision (codes 410 to 414 for coronary heart disease [CHD],

9 codes 430 to 438 for cerebrovascular diseases and codes 390 to 458 for CVD)(30). Because the

10 underlying cause of death in elderly people is often difficult to ascertain, we included primary

11 and secondary causes of cardiovascular death.

\section{Statistical analysis}

14 Cox proportional hazard analyses with age as the time variable $(31 ; 32)$ were performed using the

15 PHREG procedure of SAS/STAT software (version 9.1; SAS Institute, Inc, Cary, NC). Time at

16 entry was age on December $31^{\text {st }}$ in the year preceding the year the men participated in both the

17 dietary and physical examinations for the first time, i.e. the first measurement round; exit time

18 was age at death, age when lost to follow-up, or age when censored, whichever came first. We

19 calculated the cumulative average alcohol intake to better represent long-term intake. With this

20 method, exposure between 1960 and 1965 was calculated from the alcohol intake from the 1960

21 examination round; exposure between 1965 and 1970 was calculated from the average alcohol

22 intake from the 1960 and 1965 examination rounds, and so on (17). For those men who were

23 newly included in the study in 1985, information on alcohol intake was missing in the period

24 1960-1970. To take into account that average alcohol intake was higher in 1985 than in 1960- 
$1 \quad 1970$ and that taking cumulative averages excluding earlier intakes in those men who were newly

2 in the study in 1985 would overestimate their intake compared to men included in 1960, multiple

3 imputation (33), five times, of alcohol intake and dietary covariates between 1960 and 1970 was

4 carried out with an adapted version of predicted mean matching (34). The SAS code that was

5 used for the multiple imputation can be downloaded from www.rivm.nl/sasmacros. Analyses on

6 long-term alcohol intake were performed on five imputed datasets and results were pooled using

7 the MIANALYZE procedure of SAS/STAT software.

The covariates in the multivariable models included an indicator variable for former

9 drinker, energy intake without alcohol ( $\mathrm{kcal} / \mathrm{d})$, consumption of vegetables $(\mathrm{g} / \mathrm{d})$, fruit $(\mathrm{g} / \mathrm{d})$ and

10 fish $(\mathrm{g} / \mathrm{d})$, intake of saturated and trans fatty acids $(\mathrm{g} / \mathrm{d})$, BMI $(\mathrm{kg} / \mathrm{m} 2)$, cigar or pipe smoking

11 (never and long-term ex, recent-ex and current), cigarette smoking duration (divided by 10

12 years), the daily number of cigarettes smoked (divided by 10), prevalence of MI (yes or no),

13 stroke (yes or no), DM (yes or no), and cancer (yes or no), and indicator variables for baseline

14 socioeconomic status. In additional analyses, the multivariable models for, respectively, alcohol

15 from beer, wine and spirits were additionally adjusted for total alcohol intake to investigate the

16 independent effects of alcohol from one specified alcoholic beverage type. In the multivariable

17 analyses, the cumulative average intake of all dietary covariates was calculated and non-dietary

18 covariates were updated at each measurement round. To test the proportional hazards assumption,

19 a product term between alcohol intake and age was included in the model, and a p-value for

20 interaction $<0.10$ was considered statistically significant.

21 We determined differences in life expectancy at age 50, i.e. average age at baseline,

22 between men with different levels of cumulative average alcohol intake, by calculating the area

23 under survival curves (35). To distinguish between the effects of alcohol intake and the effects of

24 alcoholic beverage types, we compared the life expectancies for men who consumed alcohol 
1 from wine (>0 gram per day) with those who consumed alcohol from beer and spirits and those

2 who consumed no alcohol from the specified sources, using cumulative average intake at each

3 measurement round. The men were included in the analysis during the period that they met the

4 requirements for the exposure categories concerned. Cox models, with age as the time variable

5 and stratified by categories of amount $(0,>0-20,>20 \mathrm{~g} / \mathrm{d}$ ) or source (no alcohol, alcohol from

6 wine, alcohol from beer or spirits) of alcohol intake, were used to obtain the survival curves. The

7 Cox models were adjusted for baseline covariates, i.e. dietary and smoking variables, BMI,

8 prevalence of chronic diseases, i.e. MI, stroke, DM and cancer, and socioeconomic status. Since

9 several participants used more than one type of alcoholic beverage in their usual diet and are,

10 thereby, included in different exposure categories at the same time, the COVSANDWICH

11 (AGGREGATE) statement was added to the PHREG procedure. Areas under the survival curves

12 from the five imputed datasets were pooled (33) and ninety-five percent confidence intervals

13 were obtained using the bootstrap method (36). 
RESULTS

\section{Population characteristics}

3 During 40 years of follow-up (mean survival age: 77 years) 1,130 of the 1,373 men participating

4 in the present study died (table 1). Of these deaths, 628 were cardiovascular disease (CVD)

5 deaths, 348 were coronary heart disease (CHD) deaths, and 139 were cerebrovascular deaths.

6 The percentage of alcohol users almost doubled from $45 \%$ in 1960 to $86 \%$ in 2000 (table

7 1). Among users, average alcohol consumption increased from $8 \mathrm{~g} / \mathrm{d}$ in 1960 to $18 \mathrm{~g} / \mathrm{d}$ among the

8 survivors in 1985, after which it decreased to $14 \mathrm{~g} / \mathrm{d}$ in 2000 (table 1). The percentage of wine

9 users increased remarkably from $2 \%$ in 1960 till about $40 \%$ in 2000 . This increase was observed

10 in all levels of socioeconomic status. Among users, the average number of glasses consumed

11 varied between a half and 1.5 glasses per day for wine, beer and spirits. With the exception of

12 1960, alcohol from spirits contributed the most to the total alcohol intake (figure 1). The

13 correlation between alcohol from spirits and total alcohol intake varied between 0.67 and 0.86 .

14 For alcohol intake from wine and beer, the correlations were lower.

\section{Alcohol consumption, alcoholic beverages and mortality}

17 Long-term alcohol intake was significantly and inversely associated with mortality risk (table 2).

18 Men with less than or equal to 20 grams of long-term, i.e. cumulative average, alcohol intake had

19 a 57\% lower cerebrovascular mortality risk, a 30\% lower CVD mortality risk, and a 25\% lower

20 all-cause mortality risk compared to men with no alcohol intake. The associations for more than

2120 grams of long-term alcohol intake per day were weaker than those for less than or equal to 20

22 grams of long-term alcohol intake per day.

23 In the next step, the independent effects of long-term alcohol intake from wine, beer and

24 spirits on mortality were estimated. After additional adjustment for total alcohol intake, less than 
1 or equal to 20 grams of long-term alcohol intake from wine per day-compared to no alcohol

2 intake from wine- was inversely associated with CHD (HR: 0.61 [95\%CI: 0.41 to 0.89), CVD

3 (HR: 0.68 [0.53 to 0.86]) and all-cause mortality risk (HR: 0.73 [0.62 to 0.87]; table 3). In the

4 models for CVD and all-cause mortality, less than or equal to 20 grams of long-term total alcohol

5 intake remained inversely associated with mortality (HR CVD mortality: 0.76 [0.59 to 0.97]; HR

6 all-cause mortality: 0.80 [0.67 to 0.97$]$ ). Additional analyses showed that the inverse association

7 between wine consumption and mortality was present in all socioeconomic classes. Among

8 manual workers, the HRs for long-term wine consumption were 0.63 (0.31 to 1.30) for CHD,

90.78 (0.49 to 1.23 ) for CVD and 0.78 (0.54 to 1.12 ) for all-cause mortality. Among the

10 professionals, the hazard ratios were comparable.

11 Long-term consumption of alcohol from beer and spirits was not independently related to

12 mortality (table 3). However, given the strong correlation between alcohol from spirits and total

13 alcohol intake, these findings should be interpreted with caution. Omiting the adjustment for the

14 prevalence of chronic diseases changed our results slightly but the overall conclusions remained

15 the same.

17 Alcohol consumption, alcoholic beverages and life expectancy

18 Men with a long-term alcohol intake less than or equal to 20 grams per day (on average $6 \mathrm{~g} / \mathrm{d}$ )

19 had a 2.3 years (95\%CI: 0.5 to 4.2 years) longer life expectancy at age 50 compared to those who

20 consumed no alcohol. For those men who consumed more than 20 grams of alcohol per day (on

21 average $29 \mathrm{~g} / \mathrm{d}$ ), life expectancy was 1.9 years (-1.1 to 4.9 years) longer compared to non-users.

22 Men who consumed alcohol from wine, on average $2 \mathrm{~g} / \mathrm{d}$, over a longer time period had a

232.5 years longer life expectancy at age 50 ( -0.3 to 5.3 years) compared to those who consumed 
1 alcohol from beer or spirits (on average about $8 \mathrm{~g} / \mathrm{d}$; figure 3 ) and a 4.7 years (1.6 to 7.7 years)

2 longer life expectancy compared to no alcohol users. 


\section{DISCUSSION}

2 Long-term light alcohol intake lowered cerebrovascular, total CVD and all-cause mortality risk,

3 and was associated with a longer life expectancy compared to no alcohol intake. Independent of

4 total alcohol intake, wine consumption was strongly and inversely associated with CHD, total

$5 \quad$ CVD and all-cause mortality. For long-term wine consumers, consuming on average less than

6 half a glass of wine per day, life expectancy at age 50 was about 5 years longer compared to no

7 alcohol users.

8 The major strength of this study was the collection of detailed information on the

9 consumption of different alcoholic beverages at each of seven examination rounds during 40

10 years of follow-up. This enabled us to study the effects of long-term, i.e. cumulative average,

11 alcohol intake on mortality. The use of cumulative average intakes reduces within-subject

12 variation over time and, thereby, measurement error. The detailed information on potential

13 confounders such as smoking (37-39) diet (40), and socioeconomic status (41) made it possible to

14 study the independent effect of total alcohol intake and alcohol from different types of alcoholic

15 beverages.

16 The present study also has some weaknesses. First, recent studies have observed that,

17 among men, frequency of alcohol consumption was inversely associated with coronary heart

18 disease risk, independent of the amount of alcohol consumed (42-44). Since in the present study,

19 information on alcohol consumption was collected as part of the usual diet, no data was available

20 on drinking frequency. Second, average long-term alcohol intake in the present study was

21 relatively low and most participants used more than one type of alcoholic beverage in their usual

22 diet. This may have led to less precise estimations of the effect of different types of alcoholic

23 beverages on mortality. Third, for those men who were newly included in the study in 1985,

24 information on alcohol intake was missing in the period 1960-1970. By multiple imputations of 
1 total alcohol intake, different types of alcoholic beverages and other dietary covariates in 1960-

2 1970, we were able to counter an underestimation of cumulative average intake from 1985

3 onwards for those men who were newly included in the study. We repeated our analysis among

4 the participants who were included in the study from $1960(n=875)$ and found similar

5 associations between long-term total alcohol intake and different types of alcoholic beverages,

6 and mortality. Therefore, it is unlikely that the imputation of total alcohol intake, different types

7 of alcoholic beverages and other dietary covariates among those men who were newly included

8 in the study from 1985 biased our results.

9 Our results confirm the inverse association between moderate alcohol intake, CVD and

10 all-cause mortality risk observed in other studies $(38 ; 39 ; 45-53)$. In contrast to these and other

11 studies (38;39;45;53-56), the highest exposure level was not associated with an increased

12 mortality risk. However, average alcohol intake in the highest exposure level was relatively low

$13(29 \mathrm{~g} / \mathrm{d})$ in the Zutphen Study, which may explain the lack of a positive association between

14 mortality and a higher intake level. In their meta-analysis, Corrao et al. estimated that the risk of

15 CHD mortality is lowest at 16 grams per day with a corresponding hazard ratio of 0.84 (57). In

16 the present study, the hazard ratios for CHD mortality were comparable but not statistically

17 significant (table 2).

18 Smoking might confound the association between alcohol intake and mortality. Previous

19 results from the Zutphen Study indicated that the number of cigarettes smoked as well as the

20 duration of cigarette smoking are, independently of each other, associated with mortality (58). In

21 our multivariable analyses we adjusted for these aspects of smoking. So, it is not likely that the

22 association between alcohol intake and mortality is explained by confounding due to smoking.

23 In the present study, wine consumption was associated with a lower mortality risk,

24 independent of total alcohol intake. Some studies did not demonstrate a favourable effect of one 
1 specific type of alcoholic beverage over another $(14 ; 42)$, while others found an inverse and

2 independent association between wine consumption and mortality (13;59-61). In the present

3 study, $70 \%$ of all wine consumed was red wine. This suggests that the cardioprotective effect of

4 wine could be due to a protective effect of polyphenolic compounds in red wine, but other

5 explanations can not be ruled out.

Socioeconomic status might confound the association between wine consumption and

7 mortality. However, in our multivariable analyses we adjusted for socioeconomic status, based on

8 occupation at baseline. At the start of the present study, the men were already in a later phase in

9 their careers and baseline socioeconomic status was considered to be a good indicator during the

10 follow-up period. Furthermore, the increase in the percentage of wine users during follow-up was

11 observed in all levels of socioeconomic status, and additional stratified analyses showed that the

12 inverse association between wine consumption and mortality was present in all socioeconomic

13 classes. These results suggest that the association between wine consumption and mortality can

14 not be explained by confounding due to socioeconomic status.

15 Long-term wine consumers had about 5 years longer life expectancy at age 50 compared

16 to no alcohol users. Of these 5 years, about 2 years can be attributed to an effect of alcohol intake

17 and is in accordance with the inverse association between long-term alcohol intake and all-cause

18 mortality found in the present study. The remainder 3 years can be attributed to an effect of wine

19 consumption. However, given the wide confidence interval, the effect of wine as such may be

20 overestimated. To our knowledge, we are the first who studied the effects of absolute alcohol

21 intake and type of alcoholic beverage on life expectancy and more studies are needed to verify

22 our results.

23 In conclusion, long-term light alcohol intake is associated with a lower risk of

24 cardiovascular and all-cause mortality risk, and a longer life expectancy. The inverse associations 
1 between wine consumption and mortality remained after adjustment for total alcohol intake.

2 Wine consumers had a 5 years longer life expectancy compared to no-alcohol consumers;

3 however, more studies are needed to draw conclusions on the strength of the association between

4 wine consumption and mortality. 


\section{Acknowledgements}

2 This work was partly supported by a grant from the former Inspectorate for Health Protection and

3 Veterinary Public Health, at present integrated in the Food and Consumer Product Safety

4 Authority, The Netherlands. 


\section{REFERENCES}

2 1. Pearson TA. Alcohol and heart disease. Circulation 1996;94:3023-5.

3 2. Sasaki S. Alcohol and its relation to all-cause and cardiovascular mortality. Acta Cardiol $4 \quad 2000 ; 55: 151-6$.

5 3. Sesso HD, Gaziano JM. Alcohol intake and cardiovascular morbidity and mortality. Curr $6 \quad$ Opin Nephrol Hypertens 1999;8:353-7.

4. Corrao G, Bagnardi V, Zambon A, La Vecchia C. A meta-analysis of alcohol consumption and the risk of 15 diseases. Prev Med 2004;38:613-9.

9 5. Rimm EB, Williams P, Fosher K, Criqui M, Stampfer MJ. Moderate alcohol intake and

10 lower risk of coronary heart disease: meta-analysis of effects on lipids and haemostatic 11 factors. BMJ 1999;319:1523-8.

12 6. Agarwal DP. Cardioprotective effects of light-moderate consumption of alcohol: a review 13 of putative mechanisms. Alcohol Alcohol 2002;37:409-15.

14 7. Burns J, Crozier A, Lean ME. Alcohol consumption and mortality: is wine different from 15 other alcoholic beverages? Nutr Metab Cardiovasc Dis 2001;11:249-58.

16 8. Wollin SD, Jones PJ. Alcohol, red wine and cardiovascular disease. J Nutr 2001;131:14014.

9. Szmitko PE, Verma S. Antiatherogenic potential of red wine: clinician update. Am J Physiol Heart Circ Physiol 2005;288:H2023-30. 
endothelial nitric oxide synthase: a mechanism that may contribute to its beneficial cardiovascular effects. J Am Coll Cardiol 2003;41:471-8.

11. Leikert JF, Rathel TR, Wohlfart P, Cheynier V, Vollmar AM, Dirsch VM. Red wine polyphenols enhance endothelial nitric oxide synthase expression and subsequent nitric oxide release from endothelial cells. Circulation 2002;106:1614-7.

12. Di Castelnuovo A, Rotondo S, Iacoviello L, Donati MB, De Gaetano G. Meta-analysis of wine and beer consumption in relation to vascular risk. Circulation 2002;105:2836-44.

13. Gronbaek M. Alcohol, type of alcohol, and all-cause and coronary heart disease mortality. Ann N Y Acad Sci 2002;957:16-20.

14. Rimm EB, Klatsky A, Grobbee D, Stampfer MJ. Review of moderate alcohol consumption and reduced risk of coronary heart disease: is the effect due to beer, wine, or spirits. BMJ

15. Barefoot JC, Gronbaek M, Feaganes JR, McPherson RS, Williams RB, Siegler IC. 1996;312:731-6.

16. Panagiotakos DB, Pitsavos C, Arvaniti F, Stefanadis C. Adherence to the Mediterranean food pattern predicts the prevalence of hypertension, hypercholesterolemia, diabetes and obesity, among healthy adults; the accuracy of the MedDietScore. Prev Med 2007;44:335-

17. Hu FB, Stampfer MJ, Rimm E, Ascherio A, Rosner BA, Spiegelman D, Willett WC. 
1 energy intake and modeling repeated dietary measurements. Am J Epidemiol

$2 \quad 1999 ; 149: 531-40$.

3 18. Burke BS. The dietary history as a tool in research. J Am Diet Assoc 1947;23:1041-1046.

4 19. Den Hartog C, Van Schaik ThFSM, Dalderup LM, Drion EF, Mulder T. The diet of

5 volunteers participating in a long term epidemiological field survey on coronary heart

6 disease at Zutphen, the Netherlands. Voeding 1965;26:184-208.

20. Kromhout D, de Lezenne Coulander C, Obermann-de Boer GL, van Kampen-Donker M, Goddijn E, Bloemberg BP. Changes in food and nutrient intake in middle-aged men from 1960 to 1985 (the Zutphen Study). Am J Clin Nutr 1990;51:123-9.

21. Stichting NEVO. NEVO Tabel, Nederlands Voedingsstoffenbestand 1986-1987, 19891990, 1996 \& 2001. Den Haag: Voedingscentrum (voorheen Voorlichtingsbureau voor de Voeding), 1986, 1989, 1996 and 2001.

22. Beemster CJM, Hulshof KFAM, Breedveld BC, Westenbrink S. Creation of a database for the calculation of nutrient intake over time. J Food Comp Anal 2000;13:411-47.

23. Streppel MT, Ocké MC. Een voedingsmiddelentabel voor het uitvoeren van trendanalyses in de Zutphen Studie. Bilthoven: RIVM, 2005. [in Dutch]

24. Bloemberg BP, Kromhout D, Obermann-De Boer GL, Van Kampen-Donker M. The reproducibility of dietary intake data assessed with the cross-check dietary history method. Am J Epidemiol 1989;130:1047-56.

25. Kromhout D, Nissinen A, Menotti A, Bloemberg B, Pekkanen J, Giampaoli S. Total and 
HDL cholesterol and their correlates in elderly men in Finland, Italy, and The Netherlands. Am J Epidemiol 1990;131:855-63.

26. Wannamethee SG, Shaper AG. Lifelong teetotallers, ex-drinkers and drinkers: mortality and the incidence of major coronary heart disease events in middle-aged British men. Int J Epidemiol 1997 ;26:523-31.

27. Klatsky AL, Armstrong MA, Friedman GD. Risk of cardiovascular mortality in alcohol drinkers, ex-drinkers and nondrinkers. Am J Cardiol 1990;66:1237-42.

28. Shaper AG. Alcohol and mortality: a review of prospective studies. Br J Addict $1990 ; 85: 837-47$.

29. Menotti A, Blackburn H, Kromhout D, Nissinen A, Fidanza F, Giampaoli S, Buzina R,

11 Mohacek I, Nedeljkovic S, Aravanis C, Toshima H. Changes in population cholesterol levels and coronary heart disease deaths in seven countries. Eur Heart J 1997;18:566-71.

13 30. International Classification of Diseases, 8th Revision. Geneva: World Health Organization, $14 \quad 1965$.

15 31. Thiebaut AC, Benichou J. Choice of time-scale in Cox's model analysis of epidemiologic cohort data: a simulation study. Stat Med 2004;23:3803-20.

17 32. Korn EL, Graubard BI, Midthune D. Time-to-event analysis of longitudinal follow-up of a

18 survey: choice of the time-scale. Am J Epidemiol 1997;145:72-80.

19 33. Rubin DB. Multiple Imputation for nonresponse in surveys. New York: Wiley, 1987.

20 34. Lazzeroni LG, Schenker N, Taylor JMG. Robustness of multiple imputation techniques to 
model misspecification. American Statistical Association's 1990 Proceedings of the Survey Research Methods Section 1990;260-265.

35. Rao SR, Schoenfeld DA. Survival methods. Circulation 2007;115:109-13.

36. Efron B and Tibshirani RJ. An introduction to the bootstrap. Monographs on statistics and applies probability No. 57. New York: Chapman \& Hall, 1993.

37. Sulander T, Helakorpi S, Rahkonen O, Nissinen A, Uutela A. Smoking and alcohol consumption among the elderly: trends and associations, 1985-2001. Prev Med 2004;39:413-8.

38. Thun MJ, Peto R, Lopez AD, Monaco JH, Henley SJ, Heath CW Jr, Doll R. Alcohol consumption and mortality among middle-aged and elderly U.S. adults. N Engl J Med $1997 ; 337: 1705-14$

39. Tsugane S, Fahey MT, Sasaki S, Baba S. Alcohol consumption and all-cause and cancer

13 mortality among middle-aged Japanese men: seven-year follow-up of the JPHC study Cohort I. Japan Public Health Center. Am J Epidemiol 1999;150:1201-7.

40. Forsander OA. Dietary influences on alcohol intake: a review. J Stud Alcohol 1998;59:2631.

41. Nielsen NR, Schnohr P, Jensen G, Gronbaek M. Is the relationship between type of alcohol and mortality influenced by socio-economic status? J Intern Med 2004;255:280-8. 
disease in men. N Engl J Med 2003;348:109-18.

43. Mukamal KJ, Jensen MK, Gronbaek M, Stampfer MJ, Manson JE, Pischon T, Rimm EB. Drinking frequency, mediating biomarkers, and risk of myocardial infarction in women and men. Circulation 2005;112:1406-13.

44. Tolstrup J, Jensen MK, Tjonneland A, Overvad K, Mukamal KJ, Gronbaek M. Prospective study of alcohol drinking patterns and coronary heart disease in women and men. BMJ $2006 ; 332: 1244-8$.

45. Gronbaek M, Johansen D, Becker U, Hein HO, Schnohr P, Jensen G, Vestbo J, Sorensen TI. Changes in alcohol intake and mortality: a longitudinal population-based study. Epidemiology 2004;15: 222-8.

46. Berger K, Ajani UA, Kase CS, Gaziano JM, Buring JE, Glynn RJ, Hennekens CH. Lightto-moderate alcohol consumption and risk of stroke among U.S. male physicians. N Engl J Med 1999;341:1557-64.

47. Gaziano JM, Gaziano TA, Glynn RJ, Sesso HD, Ajani UA, Stampfer MJ, Manson JE, Hennekens CH, Buring JE. Light-to-moderate alcohol consumption and mortality in the Physicians' Health Study enrollment cohort. J Am Coll Cardiol 2000;35:96-105.

48. Camargo CA Jr, Hennekens CH, Gaziano JM, Glynn RJ, Manson JE, Stampfer MJ. Prospective study of moderate alcohol consumption and mortality in US male physicians. Arch Intern Med 1997;157:79-85.

49. Cullen KJ, Knuiman MW, Ward NJ. Alcohol and mortality in Busselton, Western Australia. Am J Epidemiol 1993;137:242-8. 
50. Scherr PA, LaCroix AZ, Wallace RB, Berkman L, Curb JD, Cornoni-Huntley J, Evans DA, Hennekens $\mathrm{CH}$. Light to moderate alcohol consumption and mortality in the elderly. J Am Geriatr Soc 1992;40:651-7.

51. Lin Y, Kikuchi S, Tamakoshi A, Wakai K, Kawamura T, Iso H, Ogimoto I, Yagyu K,

5 Obata Y, Ishibashi T. Alcohol consumption and mortality among middle-aged and elderly Japanese men and women. Ann Epidemiol 2005;15:590-7.

52. Doll R, Peto R, Boreham J, Sutherland I. Mortality in relation to alcohol consumption: a prospective study among male British doctors. Int J Epidemiol 2005;34:199-204.

53. Emberson JR, Shaper AG, Wannamethee SG, Morris RW, Whincup PH. Alcohol intake in

10 middle age and risk of cardiovascular disease and mortality: accounting for intake variation 11 over time. Am J Epidemiol 2005;161:856-63.

12 54. Hart CL, Smith GD, Hole DJ, Hawthorne VM. Alcohol consumption and mortality from all 13 causes, coronary heart disease, and stroke: results from a prospective cohort study of 14 scottish men with 21 years of follow up. BMJ 1999;318:1725-9.

15 55. Theobald H, Johansson SE, Bygren LO, Engfeldt P. The effects of alcohol consumption on mortality and morbidity: a 26-year follow-up study. J Stud Alcohol 2001;62:783-9.

17 56. Farchi G, Fidanza F, Mariotti S, Menotti A. Alcohol and mortality in the Italian rural

18 cohorts of the Seven Countries Study. Int J Epidemiol 1992;21:74-81.

19 57. Corrao G, Rubbiati L, Bagnardi V, Zambon A, Poikolainen K. Alcohol and coronary heart disease: a meta-analysis. Addiction 2000;95:1505-23. 
58. Streppel MT, Boshuizen HC, Ocke MC, Kok FJ, Kromhout D. Mortality and life expectancy in relation to long-term cigarette, cigar and pipe smoking: the Zutphen Study. Tob Control 2007;16:107-13.

59. Theobald H, Bygren LO, Carstensen J, Engfeldt P. A moderate intake of wine is associated with reduced total mortality and reduced mortality from cardiovascular disease. J Stud Alcohol 2000;61:652-6.

60. Renaud SC, Gueguen R, Siest G, Salamon R. Wine, beer, and mortality in middle-aged men from eastern France. Arch Intern Med 1999;159:1865-70.

61. Klatsky AL, Friedman GD, Armstrong MA, Kipp H. Wine, liquor, beer, and mortality. Am J Epidemiol 2003;158:585-95. 


\section{Publication statement}

2 The Corresponding Author has the right to grant on behalf of all authors and does grant on behalf

3 of all authors, an exclusive licence (or non exclusive for government employees) on a worldwide

4 basis to the BMJ Publishing Group Ltd to permit this article (if accepted) to be published in

5 JECH and any other BMJPGL products and sublicences such use and exploit all subsidiary

6 rights, as set out in our licence (http://jmg.bmj.com/ifora/licence.pdf). 
TABLE 1. Characteristics of men participating in the Zutphen Study by year of measurement*

\begin{tabular}{|c|c|c|c|c|c|c|c|c|c|}
\hline \multirow{2}{*}{ No. of participants $\dagger$} & \multirow{2}{*}{\multicolumn{2}{|c|}{$\begin{array}{c}\text { Cohort } \\
1960\end{array}$}} & \multirow{2}{*}{$\begin{array}{c}1960 \\
872\end{array}$} & \multirow{2}{*}{$\begin{array}{c}1965 \\
721\end{array}$} & \multirow{2}{*}{\begin{tabular}{|l|}
1970 \\
615
\end{tabular}} & \multirow{2}{*}{\begin{tabular}{c|}
$\mathbf{1 9 8 5}$ \\
349 \\
\end{tabular}} & \multirow{2}{*}{\begin{tabular}{|c|}
1990 \\
231
\end{tabular}} & \multirow{2}{*}{\begin{tabular}{c|}
1995 \\
114
\end{tabular}} & \multirow{2}{*}{$\begin{array}{c}2000 \\
51\end{array}$} \\
\hline & & & & & & & & & \\
\hline & & 1985 & & & & 476 & 306 & 161 & 68 \\
\hline \multirow[t]{4}{*}{ Cum. no. of deaths } & All-cause & & - & 40 & 103 & 412 & 645 & 889 & 1130 \\
\hline & Total cardt & cular & - & 20 & 61 & 261 & 376 & 514 & 628 \\
\hline & Coronaryl & disease & - & 13 & 40 & 176 & 231 & 297 & 348 \\
\hline & Cerebrova & & - & 3 & 10 & 49 & 78 & 113 & 139 \\
\hline \multicolumn{3}{|l|}{ Age (years) $\ddagger$} & $49 \pm 6$ & $54 \pm 5$ & $59 \pm 5$ & $71 \pm 5$ & $75 \pm 5$ & $80 \pm 4$ & $83 \pm 3$ \\
\hline \multicolumn{3}{|c|}{ Body mass index $(\mathrm{kg} / \mathrm{m} 2)$} & $24.1 \pm 2.7$ & $24.9 \pm 2.7$ & $25.2 \pm 2.8$ & $25.5 \pm 3.1$ & $25.5 \pm 3.2$ & $25.3 \pm 3.4$ & $26.0 \pm 3.3$ \\
\hline \multirow[t]{4}{*}{ Overall smoking $(\%) \S$} & \multicolumn{2}{|c|}{ Never and long-term ex } & 6 & 6 & 9 & 26 & 50 & 60 & 72 \\
\hline & \multicolumn{2}{|l|}{ Recent ex } & 6 & 11 & 15 & 31 & 17 & 16 & 14 \\
\hline & \multicolumn{2}{|l|}{ Cigarettes } & 74 & 61 & 53 & 30 & 23 & 18 & 6 \\
\hline & \multicolumn{2}{|c|}{ Cigars or pipes } & 14 & 21 & 23 & 13 & 10 & 6 & 8 \\
\hline \multicolumn{3}{|c|}{ Energy without alcohol (kcal) } & $3082 \pm 673$ & $2920 \pm 674$ & $2539 \pm 539$ & $2146 \pm 506$ & $2029 \pm 458$ & $2029 \pm 468$ & $1991 \pm 457$ \\
\hline \multirow{2}{*}{\multicolumn{2}{|c|}{ Alcohol intake $(\mathrm{g} / \mathrm{d}) \mathrm{I}$}} & 1960 & $8 \pm 13$ & $10 \pm 13$ & $12 \pm 13$ & $18 \pm 19$ & $14 \pm 15$ & $14 \pm 14$ & $13 \pm 11$ \\
\hline & & 1985 & - & - & - & $18 \pm 17$ & $14 \pm 14$ & $13 \pm 15$ & $14 \pm 16$ \\
\hline \multirow{2}{*}{\multicolumn{2}{|c|}{ Alcohol users (\%) }} & 1960 & 45 & 62 & 72 & 75 & 78 & 80 & 86 \\
\hline & & 1985 & - & - & - & 75 & 72 & 78 & 85 \\
\hline \multirow{2}{*}{\multicolumn{2}{|c|}{ Beer users $(\%)$}} & 1960 & 38 & 35 & 42 & 24 & 22 & 22 & 37 \\
\hline & & 1985 & - & - & - & 24 & 25 & 25 & 29 \\
\hline \multirow{2}{*}{\multicolumn{2}{|c|}{ Wine users $(\%)$}} & 1960 & 2 & 5 & 6 & 20 & 26 & 29 & 39 \\
\hline & & 1985 & - & - & - & 25 & 31 & 38 & 47 \\
\hline \multirow[t]{2}{*}{ Spirits users (\%) } & & 1960 & 15 & 42 & 52 & 55 & 55 & 58 & 61 \\
\hline & & 1985 & - & - & - & 55 & 49 & 49 & 54 \\
\hline
\end{tabular}


*Numbers represent means \pm standard deviation, unless indicated otherwise

$\dagger$ In every measurement round, the participants that took part in both medical and dietary examinations were selected for the analyses $\$$ Age is defined as age on December 31 st in the year preceding the examination

$\S N e v e r$ and long-term ex-smokers are defined as men who never smoked or stopped smoking $\geq 10$ years ago; recent ex-smokers are defined as men who stopped smoking <10 years ago

IIAverage alcohol intake was calculated among alcohol users. 
TABLE 2. Long-term alcohol consumption in relation to cardiovascular and all-cause mortality within the Zutphen Study

\begin{tabular}{|c|c|c|c|}
\hline & \multirow[b]{2}{*}{ Amount } & \multicolumn{2}{|c|}{$\begin{array}{c}\text { Long-term intake } \\
\text { (cumulative average, time-dependent) }\end{array}$} \\
\hline & & $\begin{array}{l}\text { Crude HR } \\
(95 \% \mathrm{CI})^{*}\end{array}$ & $\begin{array}{l}\text { Adjusted HR } \\
(95 \% \mathrm{CI}) \dagger \neq\end{array}$ \\
\hline \multirow[t]{2}{*}{ Coronary heart disease } & $>0$ to $20 \mathrm{~g} / \mathrm{d}$ & $0.92(0.67 ; 1.25)$ & $0.80(0.57 ; 1.11)$ \\
\hline & $>20 \mathrm{~g} / \mathrm{d}$ & $0.80(0.49 ; 1.31)$ & $0.77(0.44 ; 1.33)$ \\
\hline \multirow[t]{2}{*}{ Cerebrovascular } & $>0$ to $20 \mathrm{~g} / \mathrm{d}$ & $0.44(0.28 ; 0.68)$ & $0.43(0.26 ; 0.70)$ \\
\hline & $>20 \mathrm{~g} / \mathrm{d}$ & $0.44(0.22 ; 0.92)$ & $0.56(0.25 ; 1.25)$ \\
\hline \multirow[t]{2}{*}{ Total cardiovascular } & $>0$ to $20 \mathrm{~g} / \mathrm{d}$ & $0.75(0.60 ; 0.95)$ & $0.70(0.55 ; 0.89)$ \\
\hline & $>20 \mathrm{~g} / \mathrm{d}$ & $0.78(0.56 ; 1.10)$ & $0.83(0.56 ; 1.22)$ \\
\hline \multirow[t]{2}{*}{ All Cause } & $>0$ to $20 \mathrm{~g} / \mathrm{d}$ & $0.78(0.65 ; 0.93)$ & $0.75(0.63 ; 0.91)$ \\
\hline & $>20 \mathrm{~g} / \mathrm{d}$ & $0.82(0.63 ; 1.07)$ & $0.82(0.61 ; 1.12)$ \\
\hline
\end{tabular}

*Crude HR, hazard ratio CI, confidence interval

$\dagger$ Hazard ratios are adjusted for former drinking, energy intake without alcohol, the number of cigarettes smoked, cigarette smoking duration, cigar or pipe smoking, intake of vegetables, fruit, fish, saturated fat and trans fatty acids, body mass index, prevalence of myocardial infarction, stroke, diabetes mellitus and cancer, and baseline socioeconomic status.

$\$$ Because of missing data in the covariates, the number of events is less than the number mentioned in table 1. 
TABLE 3. Long-term consumption of alcohol from beer, wine or spirits in relation to cardiovascular and all-cause mortality within the Zutphen Study

\section{Long-term intake}

(cumulative average, time-dependent)

\begin{tabular}{|c|c|c|c|c|c|}
\hline & $\begin{array}{c}\text { Alcohol } \\
\text { source }\end{array}$ & Amount & $\begin{array}{l}\text { Crude HR } \\
(95 \% \mathrm{CI})^{*}\end{array}$ & $\begin{array}{c}\text { Adjusted HR } \\
(95 \% \text { CI }) \dagger \S\end{array}$ & $\begin{array}{r}\text { Adjusted HR } \\
(95 \% \mathrm{CI}) \ddagger \S\end{array}$ \\
\hline \multirow{6}{*}{$\begin{array}{l}\text { Coronary } \\
\text { heart disease }\end{array}$} & Wine & $>0$ to $20 \mathrm{~g} / \mathrm{d}$ & $0.59(0.42 ; 0.83)$ & $0.60(0.41 ; 0.87)$ & $0.61(0.41 ; 0.89)$ \\
\hline & & $>20 \mathrm{~g} / \mathrm{d}$ & $\mathrm{NI} I$ & NI & NI \\
\hline & Beer & $>0$ to $20 \mathrm{~g} / \mathrm{d}$ & $0.86(0.68 ; 1.09)$ & $0.79(0.62 ; 1.02)$ & $0.82(0.60 ; 1.12)$ \\
\hline & & $>20 \mathrm{~g} / \mathrm{d}$ & $1.13(0.41 ; 3.08)$ & $1.02(0.35 ; 2.93)$ & $1.10(0.36 ; 3.39)$ \\
\hline & Spirits & $>0$ to $20 \mathrm{~g} / \mathrm{d}$ & $0.93(0.70 ; 1.23)$ & $0.85(0.63 ; 1.15)$ & $0.92(0.63 ; 1.34)$ \\
\hline & & $>20 \mathrm{~g} / \mathrm{d}$ & $0.86(0.40 ; 1.84)$ & $0.89(0.42 ; 1.86)$ & $1.01(0.35 ; 2.97)$ \\
\hline \multirow{6}{*}{$\begin{array}{l}\text { Cerebro- } \\
\text { vascular }\end{array}$} & Wine & $>0$ to $20 \mathrm{~g} / \mathrm{d}$ & $0.67(0.44 ; 1.01)$ & $0.82(0.53 ; 1.26)$ & $0.92(0.58 ; 1.46)$ \\
\hline & & $>20 \mathrm{~g} / \mathrm{d}$ & NI & NI & NI \\
\hline & Beer & $>0$ to $20 \mathrm{~g} / \mathrm{d}$ & $0.64(0.45 ; 0.93)$ & $0.62(0.42 ; 0.92)$ & $0.81(0.48 ; 1.35)$ \\
\hline & & $>20 \mathrm{~g} / \mathrm{d}$ & $0.68(0.09 ; 5.01)$ & $0.78(0.10 ; 6.26)$ & $0.78(0.09 ; 6.73)$ \\
\hline & Spirits & $>0$ to $20 \mathrm{~g} / \mathrm{d}$ & $0.76(0.51 ; 1.13)$ & $0.79(0.52 ; 1.20)$ & $1.44(0.72 ; 2.86)$ \\
\hline & & $>20 \mathrm{~g} / \mathrm{d}$ & $0.62(0.19 ; 1.97)$ & $0.70(0.21 ; 2.34)$ & $0.93(0.20 ; 4.32)$ \\
\hline \multirow{6}{*}{$\begin{array}{l}\text { Total cardio- } \\
\text { vascular }\end{array}$} & Wine & $>0$ to $20 \mathrm{~g} / \mathrm{d}$ & $0.63(0.51 ; 0.78)$ & $0.66(0.52 ; 0.84)$ & $0.68(0.53 ; 0.86)$ \\
\hline & & $>20 \mathrm{~g} / \mathrm{d}$ & $1.37(0.19 ; 9.78)$ & $2.45(0.33 ; 18.1)$ & $2.20(0.30 ; 16.4)$ \\
\hline & Beer & $>0$ to $20 \mathrm{~g} / \mathrm{d}$ & $0.84(0.70 ; 1.00)$ & $0.82(0.69 ; 0.99)$ & $0.91(0.72 ; 1.14)$ \\
\hline & & $>20 \mathrm{~g} / \mathrm{d}$ & $1.30(0.62 ; 2.74)$ & $1.29(0.58 ; 2.84)$ & $1.26(0.55 ; 2.88)$ \\
\hline & Spirits & $>0$ to $20 \mathrm{~g} / \mathrm{d}$ & $0.85(0.69 ; 1.04)$ & $0.82(0.66 ; 1.03)$ & $0.93(0.70 ; 1.24)$ \\
\hline & & $>20 \mathrm{~g} / \mathrm{d}$ & $0.84(0.50 ; 1.41)$ & $0.91(0.54 ; 1.55)$ & $0.88(0.47 ; 1.64)$ \\
\hline \multirow[t]{6}{*}{ All-cause } & Wine & $>0$ to $20 \mathrm{~g} / \mathrm{d}$ & $0.68(0.58 ; 0.78)$ & $0.72(0.61 ; 0.85)$ & $0.73(0.62 ; 0.87)$ \\
\hline & & $>20 \mathrm{~g} / \mathrm{d}$ & $0.79(0.11 ; 5.59)$ & $1.28(0.18 ; 9.28)$ & $1.21(0.17 ; 8.82)$ \\
\hline & Beer & $>0$ to $20 \mathrm{~g} / \mathrm{d}$ & $0.91(0.80 ; 1.05)$ & $0.89(0.78 ; 1.02)$ & $0.98(0.83 ; 1.17)$ \\
\hline & & $>20 \mathrm{~g} / \mathrm{d}$ & $1.41(0.84 ; 2.36)$ & $1.29(0.76 ; 2.19)$ & $1.37(0.74 ; 2.53)$ \\
\hline & Spirits & $>0$ to $20 \mathrm{~g} / \mathrm{d}$ & $0.86(0.75 ; 1.00)$ & $0.87(0.74 ; 1.01)$ & $0.97(0.80 ; 1.18)$ \\
\hline & & $>20 \mathrm{~g} / \mathrm{d}$ & $1.08(0.76 ; 1.53)$ & $1.02(0.67 ; 1.55)$ & $1.09(0.69 ; 1.73)$ \\
\hline
\end{tabular}




\section{*Crude HR, hazard ratio CI, confidence interval}

$\dagger$ Hazard ratios are adjusted for former drinking, energy intake without alcohol, the number of cigarettes smoked, cigarette smoking duration, cigar or pipe smoking, intake of vegetables, fruit, fish, saturated and trans fatty acids, body mass index, prevalence of myocardial infarction, stroke, diabetes mellitus and cancer, and baseline socioeconomic status

\$ Hazard ratios are adjusted for former drinking, energy intake without alcohol, the number of cigarettes smoked, cigarette smoking duration, cigar or pipe smoking, intake of vegetables, fruit, fish, saturated and trans fatty acids, body mass index, prevalence of myocardial infarction, stroke, diabetes mellitus and cancer, baseline socioeconomic status, and total alcohol intake

$\S$ Because of missing data, the number of events may be smaller than the number mentioned in table 1 II NI, because of the small number of men with $>20 \mathrm{~g}$ of long-term alcohol intake from wine the calculated hazard ratios are not informative. 


\section{Figure legends}

FIGURE 1 The contribution of alcohol from beer, wine and spirits to total alcohol intake within the Zutphen Study during 40 years of follow-up.

FIGURE 2 Survival curves for men with a long-term consumption of alcohol from wine, beer or spirits, and no alcohol consumers within the Zutphen Study, adjusted for baseline energy intake without energy from alcohol, the number of cigarettes smoked, cigar or pipe smoking, intake of vegetables, fruit, fish, saturated and trans fatty acids, body mass index, prevalence of myocardial infarction, stroke, cancer and diabetes mellitus, and socioeconomic status. 
What is already known on this subject: Light to moderate alcohol intake may lower all-cause mortality risk due to a lower cardiovascular mortality risk.

What does this study add?: The findings from this study suggest that light wine consumption lowers (cardiovascular) mortality risk, independently of total alcohol intake, and may increase life expectancy at age 50 . 


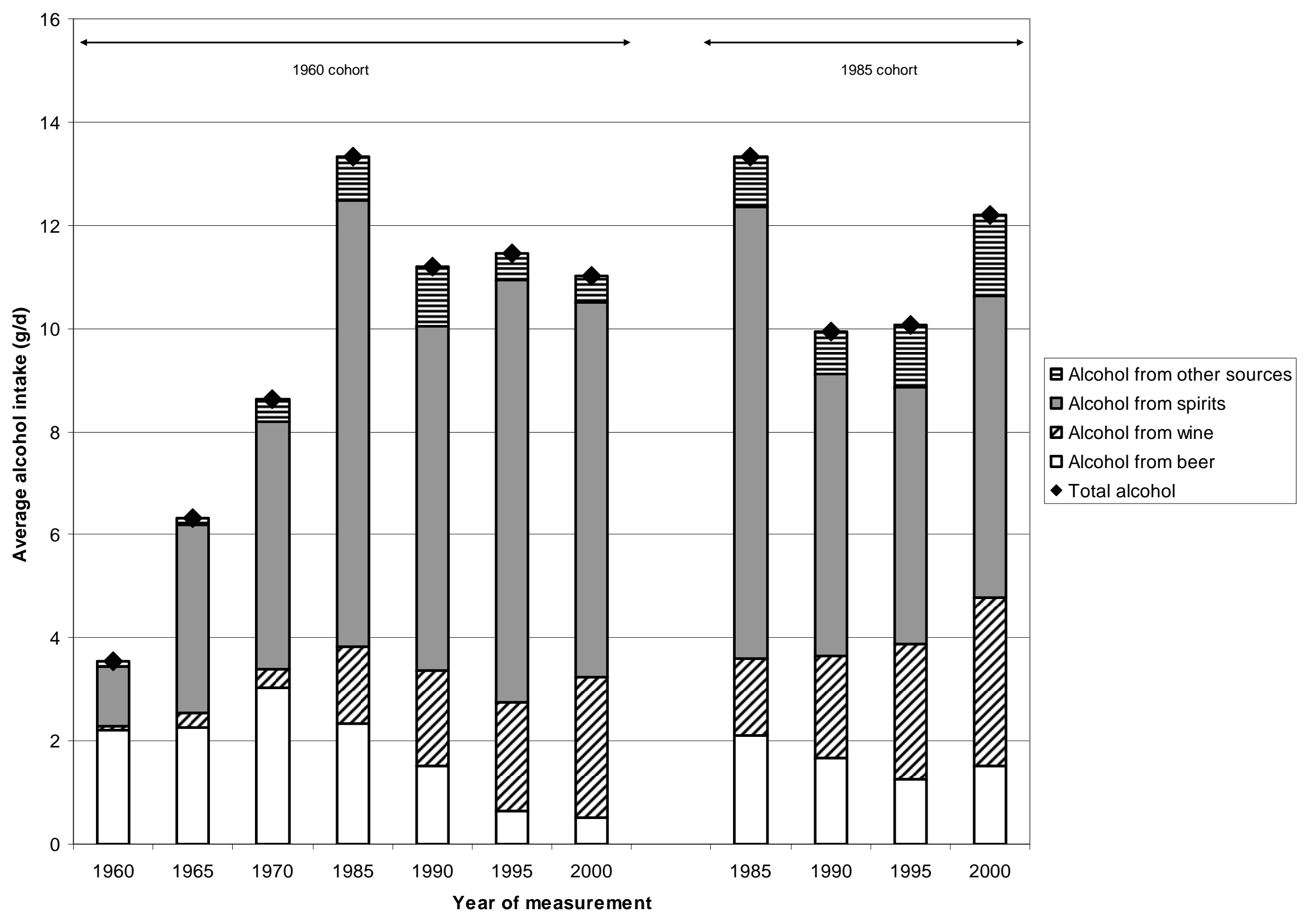




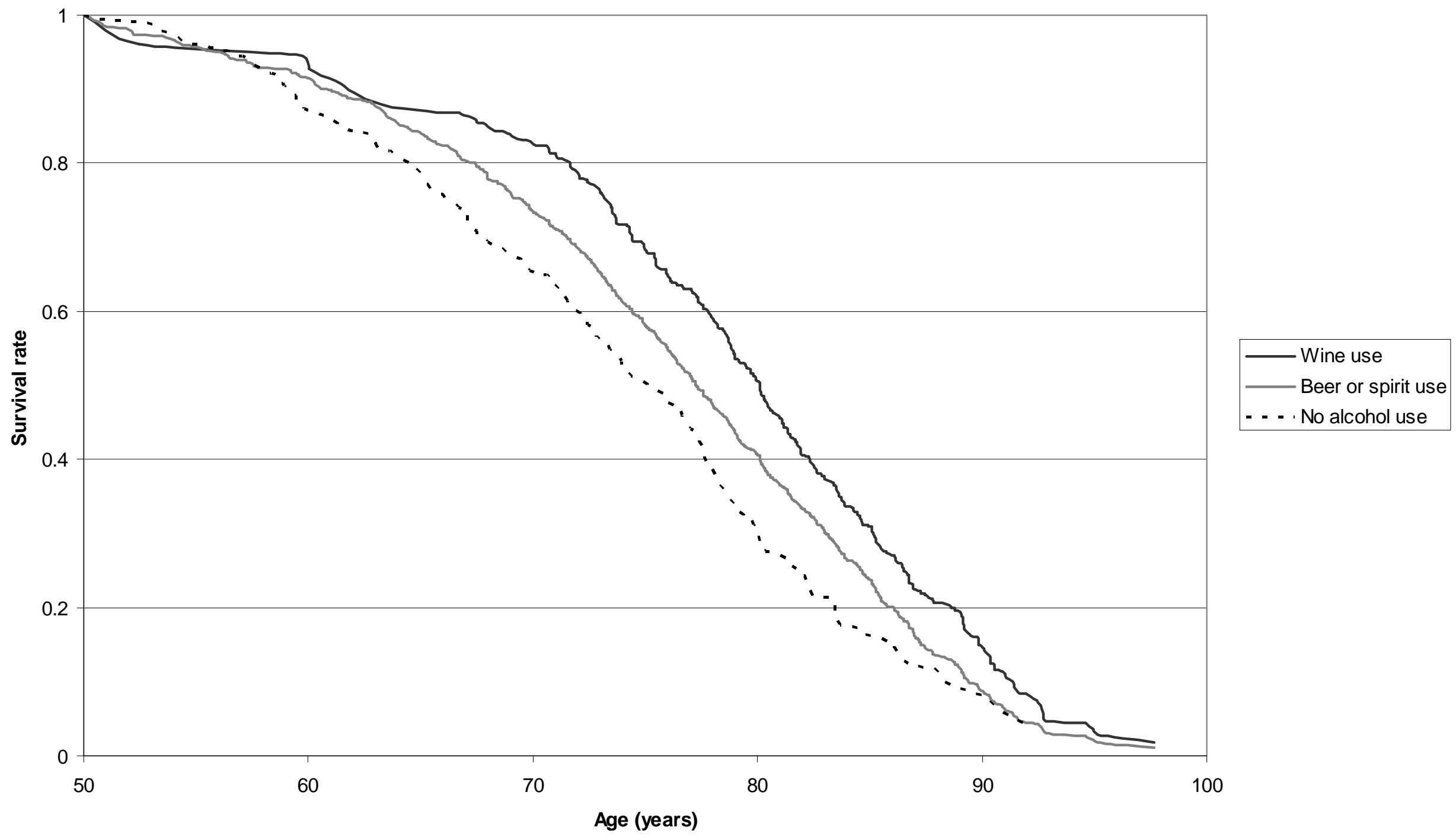

